\title{
The Mean Pressure Field Characteristic to Persistent \\ Cold Waves in the Far East
}

\author{
By Ken Suda \\ Japan Meteorological Agency, Tokyo, Japan \\ (Manuscript received 31 May 1957)
}

\begin{abstract}
The pressure patterns characteristic to extreme warmth and coldness in north Japan are compared with each other on various composite maps and $500 \mathrm{mb}$ correlation field. It is found that the eastward shift of the Far Eastern permanent trough due to the combined effect of the geographical condition of the Far East and the decrease of zonal index is responsible to the large scale cold waves in north Japan.
\end{abstract}

\section{Introduction}

Strong cold waves arriving in Japan are characterized by a clear-cut pressure pattern composed of a well-developed Siberian high and an intense Aleutian low. Because of its frequent occurrence in colder season and its importance in forecast, the pressure pattern has long been familiar to the Japanese meteorologists as the "west-higheast-low" pattern [1], and many studies have been made on it [2]. However, for the difficulty in collecting regularly weather reports from wide areas, they are mostly concerned with the weather condition in rather small area around Japan and few is known about the relationship of the west-high-east-low pattern to the general circulation of the atmosphere.

In an attempt to obtain a rough sketch of the broad-scale aspects of the cold waves in the Far East, ten cases where extremely low 5-day mean temperature was recorded at Miyako (585, in north Japan) were chosen from the colder season of three years 1954-56 and composite maps covering the whole eastern Asia and western Pacific were constructed for the same 5-day periods. At the same time, composite maps of ten cases with extremely high 5-day mean temperature at Miyako in the same 3-year period were also constructed, and the both sets of composite maps were compared with each other. The component 5-day periods are as follows :

Low temperature cases: Jan. 21-25, Jan. 26-30, Mar. 7-11, Sept. 12-16, Oct. 8-12, 1954; Nov. 7-11, 1955; Nov. 17-21, Nov. 22-26, Nov. 27-Dec. 1, Dec. 17-21, 1956.

High temperature cases : Jan. 6-10, Feb. 10-14, Feb. 25-Mar. 1, Dec. 7-11, 1954; Jan. 31-Feb. 4, Mar. 17-21, Dec. 2-6, Dec. 12-16, 1955; Mar. 17-21, Nov. 2-6, 1956.

2. Characteristic features of pressure distribution for cold and warm spells in north Japan.

Composite maps of 5 -day mean surface pressure for extremely high and extremely low temperatures in north Japan are shown in Fig. 1a. and 1b. Isobars are drawn for each $2 \mathrm{mb}$ and the centers of highs above $1040 \mathrm{mb}$ and the centers of lows below 1000 $\mathrm{mb}$ appearing on the component daily maps are entered with crosses and dots res. pectively. As will be seen in these, in the case of severe coldness the Siberian high and the Aleutian low are both strong and located in lower latitudes as compared to the case of mild temperature. In consequence of this, the pressure gradient in north Japan is much stronger indicating that fresh cold air from northeast Siberia reaches north Japan more directly than in the case of warmth. In terms of the in dividua lower 1 ward de ritories warm $\mathrm{p}$ both di and are

Then, conditio patterns composi and colc the same with the

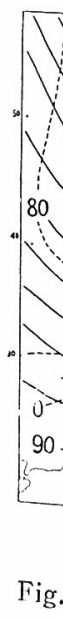

Fig. 


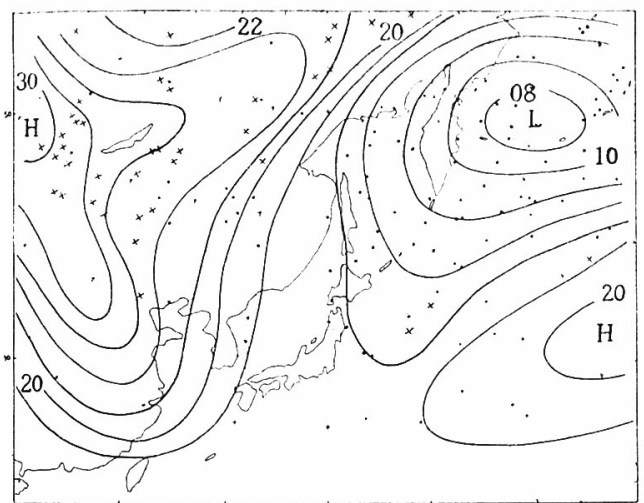

(a)

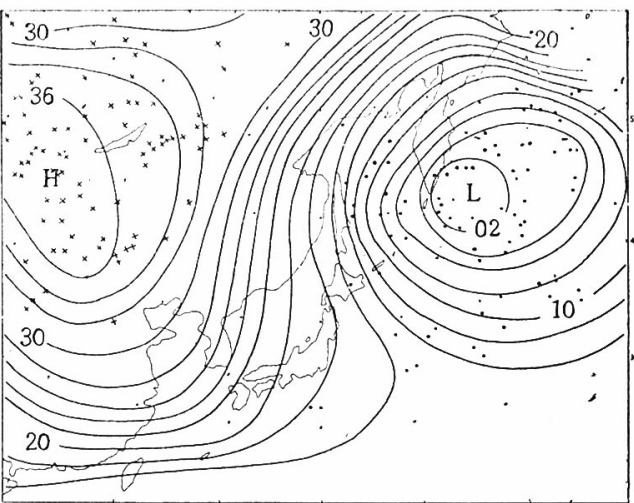

(b)

Fig. 1. Composite maps of 5-day mean surface pressue for 10 warm (a) and 10 cold (b) periods in winter season at Miyako. Isobars are drawn $2 \mathrm{mb}$ apart. Centers of lows $(\leqq 1000 \mathrm{mb}$ ) and highs $(\geqq 1040 \mathrm{mb}$ ) in component periods are entered with dots and crosses.

5, Jan.

$8-12$

Nov. 1956.

), Feb.

$1954 ;$

6, Dec. 1956.

re dis.

ells in

surface

remely shown wn for above bw 1000 daily ots resin the high ig and red to conseent in icating Siberia than in the in

dividual pressure centers, lows develop in lower latitudes and highs intrude southward deep into Mongolian and Chinese territories in cold periods in contrast to the warm periods when the lows and highs are both distributed in more zonal direction and are confined in higher latitudes.

Then, it may be asked by what upper air condition such different surface pressure patterns arise. To answer this question, composite maps of $500 \mathrm{mb}$ contour for warm and cold spells are constructed based on the same ten 5-day periods mentioned above with the result as shown in Fig. $2 \mathrm{a}$ and $2 \mathrm{~b}$.

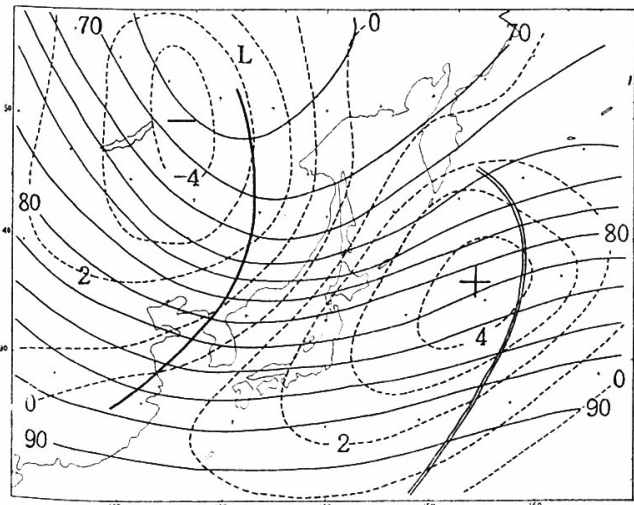

(a)
On the maps isolines of the anomaly computed on the basis of normal values [3] are also drawn, in order to facilitate the comparative study of the both situations. Contours and isoanomalies are drawn each $200 \mathrm{ft}$ and $100 \mathrm{ft}$ apart respectively.

Comparison of the maps reveals the characteristic features of upper air pressure field for the cases of warmth and coldness as follows :

In the case of warmth, the upper air low is situated to the northeast of Lake Baikal and the Far Eastern trough is extending from it southward to the mouth of Yangtze

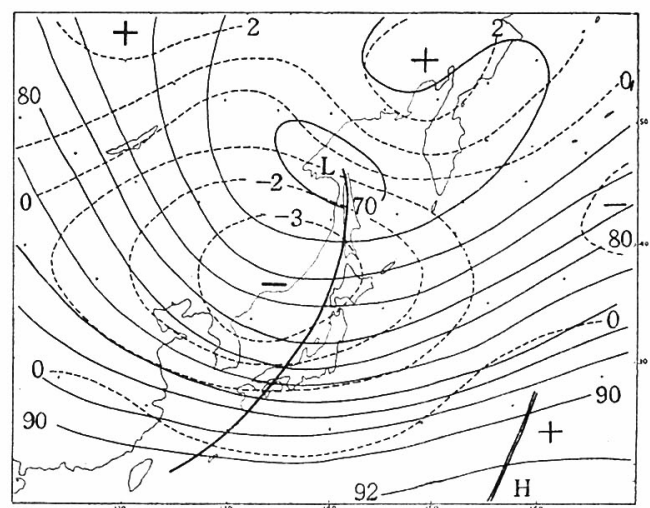

( b )

Fig. 2. Composite maps of 5-day mean $500 \mathrm{mb}$ height and anomaly for 10 warm(a) and 10 cold (b) periods in winter season at Miyako. Contours in full and isoanomalies in dashed lines are drawn 200 and $100 \mathrm{ft}$ apart respectively. 
River. The Pacific area to the east of Japan is covered by a vast positive anomaly of $500 \mathrm{mb}$ level height and a ridge is extending from Kamchatka southwestward. Contours are relatively zonal and are packed over north Japan. In contrast to this, in the case of coldness the low is displaced southeastward and located on the west coast of Okhotsk Sea. The Far Eastern trough is displaced eastward accordingly and runs nearly parallel to the Japanese Islands. The middle latitude zone including western Pacific, Japan, Manchuria and north China is covered by an extensive negative anomaly of $500 \mathrm{mb}$ level height centered in Littoral Province of the U.S.S.R., whereas northeastern Siberia and southern Pacific to the north and south of this zone show positive anomaly. Contours run southeastward over the continent and are closely packed to the south of Japan.

The contrast of $500 \mathrm{mb}$ height anomalies between both cases can be shown more

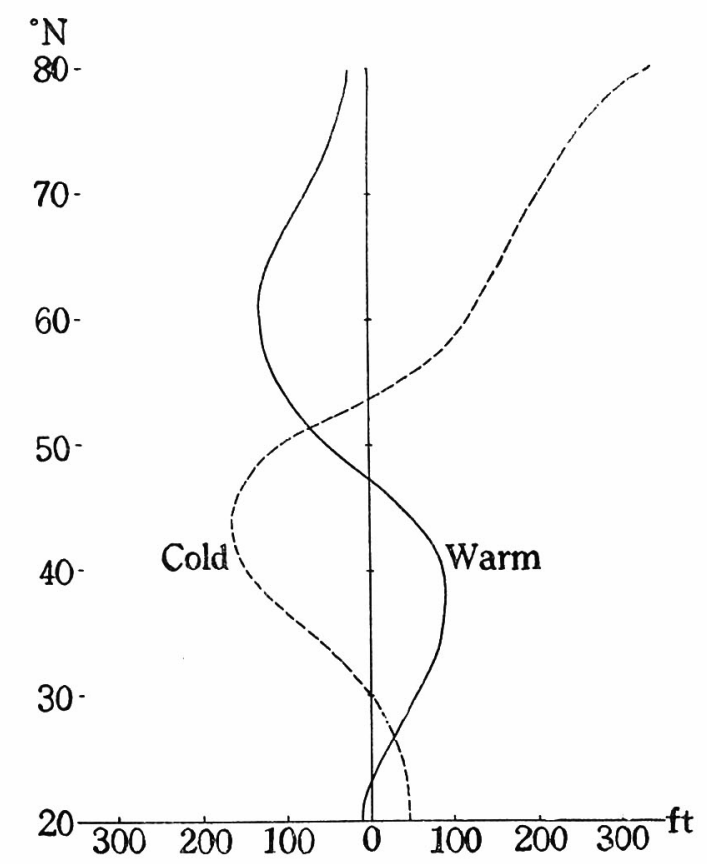

Fig. 3. Averaged meridional profile of $500 \mathrm{mb}$ height anomaly for warm (full) and cold (dashed) periods at Miyako. Ordinate in degrees of latitude, abscissa in feet. clearly by the meridional profile of anoma. lies averaged for the longitudinal range from $90^{\circ} \mathrm{E}$ to $180^{\circ}$ as shown in Fig. 3 .

As can readily be seen from this, the meridional distribution of anomalies is perfectly reversed for the cases of warmth and coldness: when it is warm (cold) in north Japan the $500 \mathrm{mb}$ level surface is high (low) in middle latitudes and low (high) in subpolar and subtropical regions. The curves indicate also that the westerlies of the middle latitudes are shifted north ward in the case of warmth while it is shifted southward in the case of coldness, since the maximum of northward gradient of anomalies is observed to the north of $40^{\circ} \mathrm{N}$ in the former case and to the south of it in the latter.

3. Extreme warmth and coldness in north Japan as related to abnormality in the general circulation of the atmosphere.

The result of comparative study described in the last section suggests that the extreme warmth and coldness in north Japan are not local phenomena but manifestations respectively of high and low index situa. tion of the general circulation [4]. Thus the characteristic features of the pressure patterns for respective temperature condition may be interpreted by the state of westerlies as follows.

In the colder season the continent is cooled by outgoing radiation and a vast amount of cold air-mass is produced on it. Now if the high index situation prevails the air-mass exchange in middle latitudes is weak so that the temperatue contrast between the continent and the ocean in. creases. As a result, an upper air cyclone is formed over northeastern Siberia where the cold pole in winter is located [5]. In consequence of this, the Far Eastern perma. nent trough, which is formed dynamically by orographic influence [6] is shifted west. ward from its average position and stays in the continent. In such condition, Japan 
anoma.

range

Fig. 3

nis, the

is per-

warmth

old) in

face is

nd low

egions,

sterlies

north.

$\mathrm{e}$ it is

ldness,

radient

orth of

south

north

in the

ohere.

scribed

the ex.

Japan

stations

situa.

Thus

ressure

condi-

tate of

hent is

a vast

on it.

revails

titudes

ontrast

ean in-

cyclone

where

5]. In

perma.

mically

d west

stays

Japan is favored with mild weather as it is situated to the east of the trough and the wind prevailing there has more southerly component than normal. Since the cold air-mass is confined in the higher latitudes owing to the weak air-mass exchange, it has little chance to penetrate into southern latitudes as anticyclones. Furthermore, since the frontal zone represented by the packing of contours on the mean chart is located to the north, cyclonic activity is weak over the seas adjacent to Japan. By reason of this, development of the west-high-east-low pattern is meager in the case of high-index.

On the other hand, if the zonal index drops and the air-mass exchange in middle latitudes strengthens, warm air of lower latitudes invades the source region of continental air-mass and the latter, in its turn, moves to the south and is transported over the ocean, thus weakening the temperature contrast between the continent and the ocean. As the result, the Far Eastern trough moves eastward from its normal position and extends along Japan. As the frontal zone is displaced to the latitude of South Japan, the cold air moves southward without being hindered by the strong westerlies and forms anticyclones on the Chinese continent. To the east of the trough, vorticity is created due to the contact of the cold continental air with

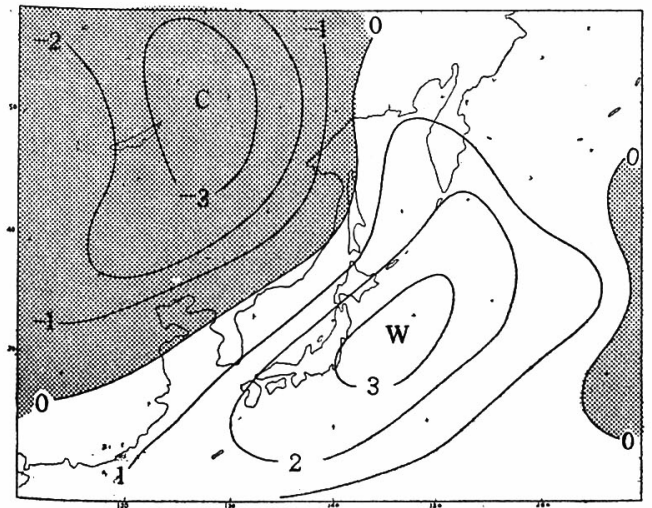

the warm ocean surface and the disturbances forming on the frontal zone develop rapidly into cyclones over the seas east of Japan [7]. Thus in the case of low index situation the west-high-east-low pattern develops with strengthening of pressure gradient over Japan.

The above reasoning can be verified on the thermal field for the cases of extreme coldness and warmth in north Japan. In Fig. $4 \mathrm{a}$ and $4 \mathrm{~b}$ are shown the composite maps of thickness anomaly between the two levels of $1000 \mathrm{mb}$ and $500 \mathrm{mb}$ constructed on the same materials as in Figs. 1 and 2. $1000 \mathrm{mb}$ height is computed from the surface pressure and the anomaly is taken in making use of [3] and [8]. As will be seen from these, in the case of warmth in north Japan (Fig. 4 a), the cold center is situated to the northeast of Lake Baikal, whereas the western Pacific is covered by an extensive warm area, the boundary belt between them running nearly parallel to the coast line. This shows the weakness of air-mass exchange in middle latitudes, especially between the continent and the ocean. On the contrary, in the case of coldness in north Japan, the cold area is centered over eastern Manchuria and extends east and west along the latitudinal circle, with a warm area to its north. This points to the fact that the increased air-

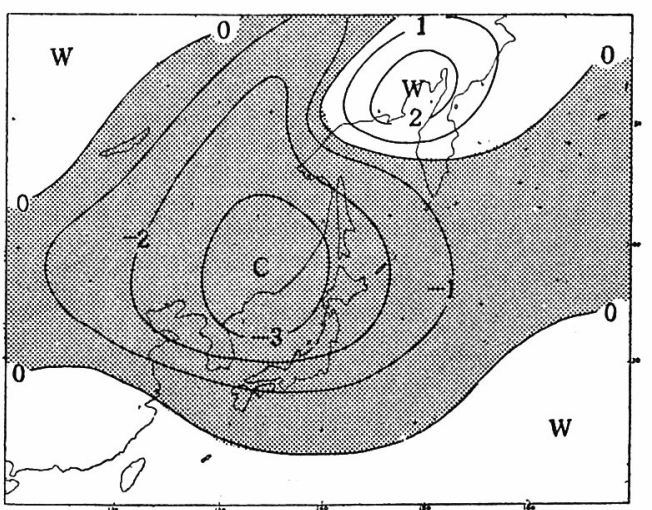

Fig. 4. Composite maps of 5-day mean thickness anomaly between $1000 \mathrm{mb}$ and $500 \mathrm{mb}$ for 10 warm (a) and 10 cold (b) periods. Isoanomalies are drawn $100 \mathrm{ft}$ apart. Areas of negative anomaly are shaded. 
mass exchange raises the temperature on the continent and lowers the temperature on the ocean.

\section{Temperature of north Japan in relation to the world pressure distribution.}

Frorn the comparative study of composite maps, it is concluded in the last section that warmth or coldness occurs in the case of high or low index situation in the general circulation. As these conclusions, however, are reached on the basis of a limited number of extreme cases, they should be tested of their generality with more numerous data. Furthermore, the spatial extent of the pressure pattern characteristic to high index and low index situations should be examined.

To meet these requirements, 5-day mean temperature at Miyako in the colder season (October to March) is correlated with 5- day mean $500 \mathrm{mb}$ height at the gridpoints chosen all over the world each 10 degrees of longitude and latitude apart. As the basic material 222 charts covering colder seasons of six years from 1951 to 1956 were used and the number of cases where the sign of $500 \mathrm{mb}$ height anomaly at those points coincided with that of the temperature anomaly at the key point (Miyako) was counted. The number is then divided by 222 and the result is represented in percentage as shown in Fig. 5. Isolines are drawn for each $5 \%$ and the area with percentages greater (smaller) than $50 \%$ is interpreted as the area of positive(negative) correlation.

As can be seen from this, the polar region is covered by a broad area of negative correlation whereas the positive area centered to the east of the key point (marked by a black circle) extends from north degree genera situati low pi pressu favora in Jap with $\mathrm{t}$ liable

The negati the sh from $t$ view $\mathrm{p}$ due to circula of the situati ase) of contine displac trough It is souther belt of accord belt to compos Japan related fication situatic operate sure to this co "Nulls In his statisti wester by the ponent the effe and de highs 
north India to Canada spanning nearly 180 degrees of longitude. This points to the general tendency that the high index situation of the general circulation with low pressure in higher latitudes and high pressure in middle latitudes provides a favorable condition for mild temperature in Japan, whereas the low index situation with the reversed pressure distribution is liable to bring about cold waves there.

The southward extension of the polar negative area to northeastern Siberia and the shift of the positive centre to the east from the key point seems to support the view presented in the last section. Namely, due to the combined effect of the general circulation and the geographical condition of the Far East, the high (low) index situation brings about the increase (decrease) of temperature contrast between the continent and the ocean and the ensuing displacement of the Far Eastern permanent trough to the west (east).

It is interesting to note that the whole southern Pacific is covered by an extensive belt of negative correlation. This is in accord with the presence of high pressure belt to the south of Japan as seen on our composite map for the case of cold in north Japan (Fig. 2 b, Fig. 3) and seems to be related to the southward shift and intensification of the jet stream in the low index situation. In other words, there seems to operate some mechanism which raises pressure to the south of the jet stream. In this connection we are reminded of the "Nullschicht" effect proposed by Faust. In his recent studies $[9,10]$ he found statistically that the axis of strongest westerlies or the jet stream is characterized by the maxinum ageostrophic wind component directed from left to right and that the effect contributes to the maintenance and development of lows to the left and highs to the right of the jet. Although many detailed studies would be required to prove the general applicability of the Nullschicht effect, the occurrence of the area of positive correlation in our case might possibly be explained by such a mechanism.

\section{Conclusion}

By constructing composite maps, the pressure patterns characteristic to extreme warmth and coldness in north Japan were studied. Furthermore, the correlation between the temperature in north Japan and the height of $500 \mathrm{mb}$ level was examined. As the result, it was revealed that large scale cold waves in north Japan and the west-high-east-low pattern are manifestations of low index situation in the general circulation of the atmosphere. If we consider the geographic condition of the Far East, the eastward shift of the permanent trough in low index situation may be attributed to the increase of airmass exchange in the middle latitudes and decrease of temperature contrast between the continent and the ocean.

As is stated in Introduction the purpose of the present work is just to get a rough sketch of the persistent cold waves in the Far East in relation to the general circulation. It is natural that more detailed analyses of the atmospheric processes are required to reach an adequate rule of forecasting severe cold in Japan on the extended-range basis but they are left for future studies.

\section{Acknowledgement}

Thanks are due to Dr. K. Koenuma and Dr. K. Takahashi for their encouragement and financial support given to carrying out the present study. The writer is also indebted to Miss S. Ito for her assistance in computational works. 


\section{References}

1) Okada, T., 1935 : Meteorology. Revised Edition, Iwanami, Tokyo, p. 164 (in Japanese). -2) Takahashi, K., 1955: Dynamic climatology, Iwanami, Tokyo, pp. 85-117 (in Japanese). -3) Central Meteorological Observatory, 1955: Normal data of 5-day mean $500 \mathrm{mb}$ height over the Northern hemisphere. -4) Rossby, C. G. and H. C. Willett, 1948: The circulation of the upper tropo. sphere and lower stratosphere. Science, 108. pp. 643-652. -5) Haurwitz, B. and J. M. Austin, 1944: Climatology, McGraw Hill, New York. -6) Charney, J. G. and A. Eliassen, 1949: A numerical method for predicting the perturbations of the middle latitude westerlies. Tellus, 1, pp. 3854. -7) Petterssen, S., 1956 : Weather Analysis and Forecasting, Second Edition, 1, McGraw Hill, New York, p. 327. -8) Seasonal Research Committee of Tohoku District, 1954: Normal data of 5-day mean surface pressure over the northern hemisphere. -9) Faust, H., 1953: Die Nullschicht, der Sitz des troposphärischen Windmaximums. Meteor. Rundschau, 6, p. 6. -10) Faust, H., 1954: Die Strahlströme als Erscheinungen der Nullschicht. Meteor. Rundschau, 7, 161166. 